\title{
TRABALHANDO AS DIFERENÇAS NO CAMPO DA EDUCAÇÃO: UMA EXPERIÊNCIA EXTENSIONISTA DO NUCH-UFPE
}

\section{DISCUSSING DIFFERENCES IN EDUCATION: AN OUTREACH EXPERIENCE AT THE NUCH-UFPE}

\section{RESUMO:}

Este texto se lança apresentar as reverberações de uma das atividades extensionistas do Núcleo de Cidadania Homossexual da Universidade Federal de Pernambuco (NUCH-UFPE) no ano de 2018. Nutrindo-se das discussões do campo de gênero e sexualidade, o NUCH efetivou a realização do curso de extensão "gênero, sexualidade e educação: perspectivas teóricas e movimentos de luta", em que se buscou estabelecer um debate no campo da educação, entendendo que as práticas pedagógicas, o currículo e as instituições escolares produzem desigualdades. Compreende-se, neste sentido, que as atividades de extensão corroboram para que as discussões teóricas sobre as questões de gênero e sexualidade atravessem os muros das escolas. Através do curso de extensão, debates e produções acadêmicas foram tecidas pelos encontros com professores da educação básica, estudantes de licenciatura, integrantes de ONG's e movimentos sociais, construindo possibilidades teórico-políticas para que as produções de desigualdades e diferenças sejam tensionadas.

Palavras chave: Gênero; Sexualidade; Educação.

\begin{abstract}
:
This text presents the impacts of an outreach activity carried out by the Homosexual Citizenship Center of the Federal University of Pernambuco (NUCH-UFPE, in the Portuguese acronym) in 2018. Based on discussions about gender and sexuality, NUCH offered the outreach course "Gender, sexuality and education: theoretical perspectives and struggle movements". The course aimed at establishing debates in educational spaces with the understanding that the pedagogical practices, the curriculum and school institutions produce inequalities. In this sense, it is understood that outreach activities contribute so that theoretical discussions on issues related to gender and sexuality go beyond the school environment. The outreach course stimulated debates and academic productions during the meetings with teachers of basic education, undergraduate students, and members of NGOs and social movements, building theoretical and political possibilities in order to highlight and reflect about inequalities and differences.
\end{abstract}

Keywords: Gender; Sexuality; Education.

\footnotetext{
* Aluno de Doutorado da Universidade Federal de Pernambuco (UFPE), Recife - PE, Brasil. E-mail: robsonguedes00@hotmail.com

${ }^{* *}$ Professora e aluna de Doutorado da Universidade Federal de Pernambuco (UFPE), Recife - PE, Brasil. E-mail: mitzhelena@yahoo.com.br

${ }^{* * *}$ Aluno de Mestrado da Universidade Federal de Pernambuco (UFPE), Recife - PE, Brasil. E-mail: dpsfernandes@outlook.com ${ }^{* * * *}$ Aluna de Mestrado da Universidade Federal de Pernambuco (UFPE), Recife - PE, Brasil. E-mail: isabella.juliappf5@hotmail.com
} 


\section{Introdução}

O Brasil, historicamente, vem se apresentando como o país que mais mata a população LGBT (lésbicas, gays, bissexuais, travestis, transexuais, intersexuais, nãobináries, queers), segundo dados do Grupo Gay da Bahia-GGB. A LGBTfobia é uma realidade social, e como iniciativa de combate à violência contra esse grupo social marginalizado, surge em 2004, por iniciativa do governo federal, em âmbito nacional, o Programa Brasil sem Homofobia, visando estabelecer um debate com a população acerca do preconceito e das variadas formas de violência para com o referido grupo, problemática que a sociedade brasileira negligenciava enfrentar.

No que tange às concepções da sociedade brasileira em torno da diversidade sexual, em particular, dados da UNESCO (2009) em pesquisa realizada em várias capitais brasileiras revelaram que, nas escolas recifenses, $39,6 \%$ dos meninos e $22,1 \%$ das meninas dizem não gostar de ter um colega homossexual em suas salas; $60 \%$ dos pais e $42,7 \%$ das mães revelaram que não gostariam que seus filhos tivessem um colega homossexual. Quanto ao corpo técnico das escolas, 5,8\% dos homens e 3,11\% das mulheres não gostariam de contar com a presença de homossexuais nas escolas em que trabalham.

Além disso, a despeito das novas orientações da Organização Mundial de Saúde, para $18,7 \%$ dos meninos e para $12,3 \%$ das meninas, a homossexualidade é vista como doença. São dados preocupantes, e trabalhar em quaisquer níveis da educação requer percebê-la como processo de transformação dos indivíduos nos próprios espaços em que são formados, uma vez que a escola congrega pessoas que são social, política e economicamente diferentes em razão de gênero, idade, religião, cultura, dentre outros fatores que fazem os indivíduos serem singulares e diferentes.

É neste sentido que o Núcleo de Cidadania Homossexual da Universidade Federal de Pernambuco NUCH-UFPE é vinculado originalmente ao Programa do Governo Federal Brasil Sem Homofobia, da Secretaria Especial de Direitos Humanos. A partir de 2010, o governo federal decidiu pela autonomia dos núcleos de cidadania, sendo de responsabilidade das universidades federais.

O NUCH-UFPE nasceu inicialmente da necessidade de pensar como a universidade deve articular saberes em torno de suas práticas de ensino, pesquisa e extensão que advoguem plena cidadania a corpos socialmente subalternizados: corpos LGBTs. Como projeto de extensão "trabalhar as diferenças é promover a educação", o NUCH-UFPE redimensiona suas concepções teórico-políticas e empreende suas atividades buscando construir possibilidades teórico-práticas de gênero e sexualidade na educação, passando a se chamar Núcleo de Direitos Humanos e Contemporaneidades LGBT/NUCH-UFPE, compreendendo como se torna cada vez mais importante a discussão sobre direitos humanos e pessoas LGBTs, articulando demandas de outros corpos, pensando nas dissidências e outras formas de viver para além das identidades.

O NUCH-UFPE é articulado aos Movimentos Sociais ligados aos segmentos LGBT e Negro, estabelecendo alianças com a Comissão de Direitos Homoafetivos do Ministério Público de Pernambuco-MPPE, Procuradoria de Justiça do MPPE, Organização Não GovernamentalONG LGBT de Terreiro e Movimento Negro Unificado de Pernambuco-MNU/PE. Na UFPE, sem descurar das articulações extramuros, visualizando-se a necessidade de tratar na universidade problemáticas existentes na formação acadêmica nos cursos de licenciaturas, objetivando identificar discursos e práticas LGBTfóbicas vivenciados nas salas de aula. Empreende suas atividades na extensão, percebendo-a como um importante caminho de atuação social, compreendendo que a extensão universitária, como afirmam Nascimento e Fernandes, tem almejado

seguir o caminho da síntese do saber acadêmico e do saber popular, do conhecimento e da realidade social. Por isto, tem sido a mola propulsora da universidade a caminho da sua consolidação enquanto espaço de articulação e integração com a sociedade e, nesta empreitada, tem sido exitosa na construcão permanente da indissociabilidade do ensino e da pesquisa (NASCIMMENTO; FERNANDES, 2015, p. 125). 
Situado no Centro de Educação da Universidade Federal de Pernambuco, entende como um eixo importante de suas atividades a formação de estudantes, técnicos, professores e funcionários da universidade, bem como a sociedade civil, percebendo os movimentos sociais e ONGs como importantes parceiros na construção coletiva de saberes que corroborem uma educação para as diferenças.

Neste sentido, o Centro de Educação se torna um espaço extremamente importante de produção de saberes que visem possibilitar a construção de uma identidade docente politicamente comprometida com o combate a LGBTfobia no cotidiano escolar. Dessa maneira, este texto abraça como objetivo descrever as contribuições do NUCH-UFPE no ano de 2018, apresentando uma experiência exitosa através das suas práticas extensionistas, tendo como fundamental importância estabelecer um amplo debate sobre gênero e sexualidade na educação, articulado aos outros dois eixos que constituem o fazer universitário, ou seja, a pesquisa e as práticas de ensino.

\section{Discussão teórica}

No Brasil, se localiza uma disputa que tem a escola como foco e projeto. Longe de apenas refletirmos sobre a função revolucionária atribuída à escola, de sozinha transformar o mundo através de suas práticas cotidianas, é importante se pensar acerca das potentes possibilidades pedagógicas que ainda residem em seu espaço e sob os efeitos que reverberam dessa instituição que cada dia mais é atacada.

A onda conservadora que se alastra no mundo evidencia que a Declaração Universal dos Direitos Humanos (1948) ainda não é recebida com benevolência por setores da elite e por grupos sociais que propagam e defendem discursos de ódio para com negros, mulheres, LGBTs, refugiados, indígenas etc. Diante desse contexto global, a escola ainda se apresenta como um lugar onde o debate acerca do respeito das diferenças é muitíssimo necessário, haja vista que é também no seu espaço que as desigualdades e violências são produzidas e naturalizadas.

A escola, neste sentido, se apresenta como um espaço em que, por meio de suas práticas pedagógicas, corpos LGBTs são marginalizados e violentados. Em um cotidiano violento e normativo, a instituição escolar convida corpos que escapam de suas práticas de enquadramento junto às normas a se retirarem dela, pois, como aponta Louro:

\footnotetext{
Currículos, normas, procedimentos de ensino, teorias, linguagem, materiais didáticos, processos de avaliação são, seguramente, loci das diferenças de gênero, sexualidade, etnia, classe - são constituídos por essas distinções e, ao mesmo tempo, seus produtores. Todas essas dimensões precisam, pois, ser colocadas em questão (LOURO, 1997, p. 64).
}

Louro (1997) argumenta ainda que a escola produz, em seu cotidiano, desigualdades, distinções e diferenças, sendo necessário estabelecer tensões com o próprio campo da educação, articulando-se novas produções acerca da escola e sua relação com a identidade e a diferença (SILVA, 2004).

Com vistas a tensionar a produção normativa da escola, os debates sobre gênero e sexualidades se articulam ao campo da educação frente ao desafio, ainda atual, do respeito aos direitos humanos de liberdade de livre orientação sexual e identidade de gênero. Grupos minoritários, sempre considerados pela sociedade como subalternos e marginais, foram historicamente agredidos e violentados por simplesmente não se encaixarem ou cumprirem um padrão normativo imposto por uma heterossexualidade compulsória. Os movimentos sociais, principalmente os feministas e em defesa dos direitos LGBT, pautaram, desde a década de 1960, políticas públicas que visassem a equidade de gênero, combate à violência contra as mulheres e pessoas LGBT, entre outras reivindicações. 
No âmbito da educação, os primeiros documentos oficiais que pautaram as temáticas de gênero e sexualidades, ainda que de forma inicial e muito biologizante, foram os Parâmetros Curriculares Nacionais - PCN, publicados pelo Ministério da Educação em 1997. Tendo um dos volumes o título de 'Orientação Sexual', o documento já apontava que

se a escola deseja ter uma visão integrada das experiências vividas pelos alunos, buscando desenvolver o prazer pelo conhecimento, é necessário reconhecer que desempenha um papel importante na educação para uma sexualidade ligada à vida, à saúde, ao prazer e ao bem-estar e que englobe as diversas dimensões do ser humano (BRASIL, 1997, p.114).

Localizando o debate como algo transversal durante todo o percurso escolar, o documento aglutinava em três blocos de conteúdo diversas discussões, como por exemplo: corpo e sexualidade, relações de gênero e prevenção às Doenças Sexualmente Transmissíveis - DSTs ${ }^{1}$. Tal documento fomentou a construção de caminhos para se emergir dentro da educação um campo importante de produção de conhecimento, que buscou pensar práticas pedagógicas que pudessem corroborar a construção de uma problematização das diferenças no cotidiano escolar, ainda marcado por muita desigualdade e formas de violência.

Como já referido, em 2004 foi criado, ainda no âmbito do governo federal, o programa 'Brasil sem Homofobia', visando combater o preconceito e a violência para com a população LGBT. Como fruto do programa foi lançado, em 2011, o Caderno 'Escola sem Homofobia', material pedagógico que foi perseguido e apelidado pejorativamente como 'kit-gay' por deputados vinculados ao fundamentalismo religioso, tendo sido proibida a sua distribuição nas escolas. $\mathrm{O}$ documento faz uma pertinente evidência do

\begin{abstract}
entendimento do governo brasileiro de que a escola atua como um dos principais agentes responsáveis pela produção, reprodução e naturalização da homofobia, não apenas no que se refere aos conteúdos disciplinares, mas também às interações cotidianas que ocorrem em seu interior e que são extensivas, também, ao ambiente doméstico (BRASIL, 2011, p. 8).
\end{abstract}

Percebendo igualmente a necessidade do trato dessas temáticas no cotidiano escolar, várias redes municipais e estaduais no Brasil, com o passar dos anos, perpassadas pelo incentivo da formação continuada, buscaram construir práticas pedagógicas que visassem combater as desigualdades ainda muito acentuadas no nosso país, pautando uma educação em gênero e sexualidade nas suas políticas de ensino. Os efeitos dessas políticas de ensino muitas vezes não foram satisfatórios, tanto pela falta de interesse dos professores de se abrirem para estudar e trabalhar a temática, quanto pela própria ausência de formações continuadas que abraçam gênero e sexualidade na educação como objetos de formação.

Sabendo dessa potência que ainda resta à escola, ou seja, da escola como lócus de produção de saberes, no Brasil projetos como escola sem partido e ideologia de gênero se mostram como manobras conservadoras e neoliberais que vão de encontro a uma construção histórica de lutas sociais em torno de uma escola que se paute pelo debate e vivência democrática, onde a diferença habite em seus espaços formativos. Assim, cabe então ao próprio campo da educação estabelecer contra produções que possam articular formas de enfrentamento a essa onda conservadora que fomenta e legitima formas de violência, inclusive no ambiente escolar.

\title{
Metodologia
}

O NUCH-UFPE articula metodologicamente perspectivas de gênero e sexualidade na educação para pensar práticas didático-pedagógicas que articulem discussões sobre os direitos humanos e as pessoas LGBTs. Neste sentido, se nutre de atividades de pesquisa (orientações, grupos de estudos e publicações acadêmicas), cursos de extensão, feiras antropológicas, eventos acadêmicos, além de reuniões de formação. 
Este texto se lança a apresentar e discutir as atividades realizadas pelo NUCH-UFPE no ano de 2018, através da realização do curso de extensão "Gênero, sexualidade e educação: perspectivas teóricas e movimentos de luta", visando expandir para além dos muros da universidade as temáticas e os debates no campo de gênero e sexualidade na educação, articulando novas formas de pensar a pesquisa acadêmica e a relação com a produção de conhecimento.

O curso de extensão se desenvolveu através de debates e oficinas pedagógicas realizadas com professores das redes municipais de ensino da região metropolitana do Recife, integrantes de ONGs, movimentos sociais, bem como estudantes da universidade. $\mathrm{O}$ referido curso teve como objetivo discutir as concepções sobre gênero, orientação sexual e sexo biológico (JESUS, 2012), identificando as dificuldades acerca do ensino de gênero e sexualidade por parte dos professores, além de provocar reflexões sobre a sua importância no cotidiano escolar.

\section{Resultados e Discussão}

O curso desenvolveu suas práticas didático-pedagógicas buscando indagar se a formação docente supera ou não formas de violência e discriminação face às diferentes orientações afetivo-sexuais e identidades de gênero, pensando até que ponto uma educação fundamentada nos princípios da cidadania contribui efetivamente para a democratização da educação e a inclusão de grupos socialmente vulneráveis. Pretendeu, ainda, identificar se essas práticas e discursos estão presentes na prática pedagógica e se estão ou não incorporadas no currículo.

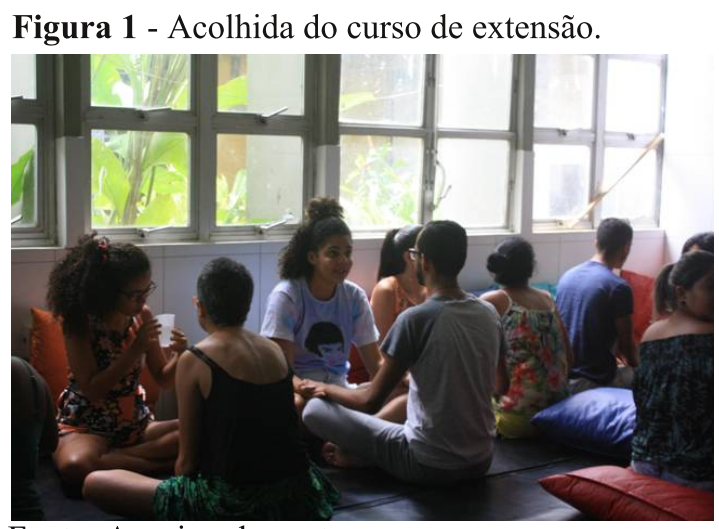

Fonte: Arquivo dos autores.

$\mathrm{Na}$ perspectiva de discutir os aspectos históricos e teóricos do campo em questão, foram trabalhadas algumas possibilidades pedagógicas sobre: questões de gênero e sexualidade a partir da ótica dos movimentos sociais e direitos humanos; reflexões feministas a partir de Simone de Beauvoir; direitos humanos e população LGBT; movimentos sociais de gênero e sexualidade na América Latina; gênero e sexualidade e educação; educação sexual: pensando possibilidades pedagógicas de enfrentamento a LGBTfobia.

O curso abraçou um duplo desafio, de um lado, construir um percurso formativo que possibilitasse aos participantes um consistente repertório dentro das temáticas de direitos humanos, gênero, sexualidade e educação. Do outro, fomentasse nos participantes um olhar investigativo, ou dito de outra maneira, práticas pedagógicas que instigassem a construção de novos olhares teórico-políticos a partir das temáticas em questão, tornando o percurso do curso um vinco entre extensão e pesquisa, evidenciando como são igualmente produtivas, de um ponto de vista cientifico, as práticas de extensão.

Os participantes, professores da rede pública, membros de ONGs, movimentos sociais e estudantes de graduação, puderam, além de problematizar os desafios que 
encontravam no cotidiano de seus engajamentos políticos e profissionais, pensar em práticas de enfrentamentos a LGBTfobia, construindo a partir das problematizações do curso de extensão objetos de pesquisa.

O curso buscou articular práticas de pesquisa em sua atividade extensionista, valorizando a construção do conhecimento, percebendo os participantes como pesquisadores engajados com problemáticas importantes do presente. Tais pesquisas detinham objetos que foram pensados a partir da realidade política e profissionais dos participantes, concebendo, neste sentido, a pesquisa acadêmica como um importante instrumento de transformação social.

Figura 2 - Encontro do curso de extensão.

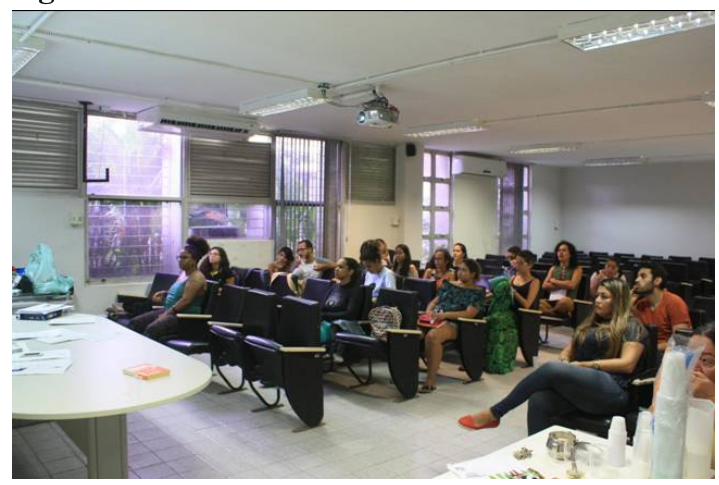

Fonte: Arquivo dos autores.

Os desafios que emergiram no decorrer do curso de extensão foram tanto as demandas cotidianas dos participantes, principalmente das professoras e professores da rede pública da Região Metropolitana do Recife-RMR, quanto as dificuldades na escrita acadêmica e autoestima para a pesquisa científica, tendo em vista que muitos participantes nunca tinham construído artigos científicos para além de seus Trabalhos de Conclusão de Curso - TCC, e entre os estudantes da graduação, poucos participantes fizeram parte de projetos de iniciação científica. Todavia, transpondo essas dificuldades, o curso conseguiu produzir práticas educativas que estimularam os participantes como investigadores. Foram produzidos como conclusão do percurso formativo do curso de extensão artigos e ensaios científicos, orientados pelos coordenadores do NUCH-UFPE.

A reverberação desse curso foi a realização do I Colóquio Universitário de Sexualidades do Centro de Educação - I CUS/CE, organizado pelos participantes do curso de extensão e pelo NUCH-UFPE, contando com ampla participação da comunidade acadêmica e sociedade civil. Propôs-se explorar as variadas contribuições que as epistemologias queer e feministas vêm oferecendo para se pensarem as relações sociais. Buscouse, também, tocar nas margens explosivas e subversivas provocadas pelos desencontros dos corpos, na teoria e na prática educativa, e como a instituição escolar se apresenta como um lugar de exclusão e disputas pelo que é normativo.

Figura 3 - I Colóquio Universitário de Sexualidades do Centro de Educação.

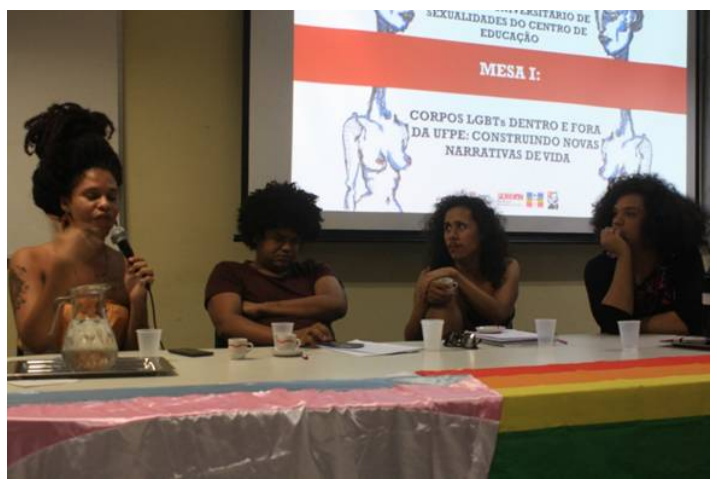

Fonte: Arquivo dos autores. 
O colóquio buscou pensar nas margens, ou seja, em torno da fragilidade dos corpos diante dos aparatos estatais de poder e dos dispositivos de regulações normalizadoras identitárias e heteronormativas (como a escola), trazendo à tona figuras erráticas: pessoas trans, travestis, não-bináries, lésbicas, bichas, sapatões, pintosas, interssexuais, queers, monstras, bizarras e demais anormalidades. Percebendo não somente os modos como os discursos se inscrevem sobre os corpos no campo da educação, mas também as possibilidades de resistência e transgressão que esses corpos apresentam, o olhar acadêmico tendeu, neste colóquio, a deslocar-se para diferentes realidades, em busca de inspiração teórico-metodológica e ativista de enfrentamento ao momento de obscurantismo que se vive no país.

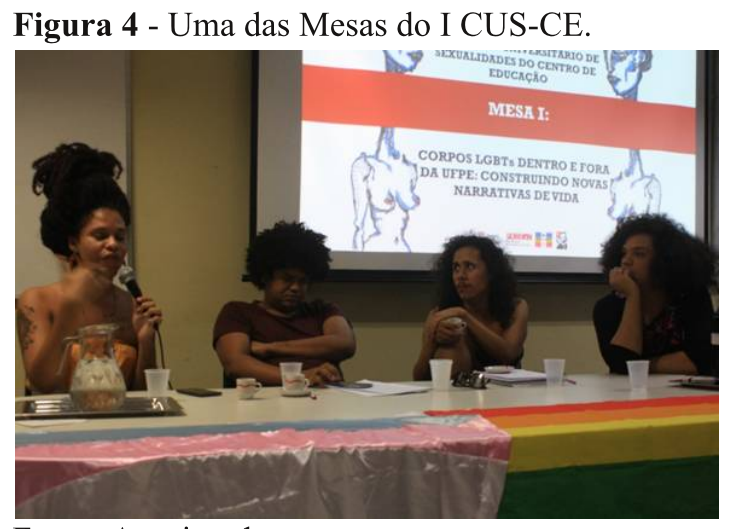

Fonte: Arquivo dos autores.

O colóquio teve como atividades de sua programação: mesas redondas, cine-debates e apresentação de trabalhos (compostas por pessoas LGBT, professores da rede e pesquisadores da universidade). Outra atividade importante do evento foi a publicação das atividades empreendidas pelo NUCH-UFPE durante o curso de extensão, em que os participantes construíram artigos e ensaios científicos reunidos na publicação do E-book "Gênero e sexualidade na educação: conceitos, enlaces e possibilidades pedagógicas", possibilitando novas formas de pensar a pesquisa acadêmica e sua relação com as práticas de extensão.

\section{Conclusões}

As atividades de extensão são importantíssimas para o fazer acadêmico, aproximando a universidade da sociedade civil, bem como socializando formas variadas de conhecimento. $\mathrm{O}$ curso de extensão "Gênero, sexualidade e educação: perspectivas teóricas e movimentos de luta" propiciou compartilhamentos de experiências cotidianas do ambiente escolar, o conhecimento de realidades difusas de atuação política e a construção de objetos de pesquisa instigantes.

Podemos, ao concluir mais um ano letivo de atividades do NUCH-UFPE, concordar com Silva et al. (2018), quando afirmam que as práticas didático-pedagógicas de gênero e sexualidade "corrobora[m] para um profundo diálogo democrático e problematizador para as questões de gênero e sexualidade na educação, sempre abordadas sobre um viés normativo, naturalizado e biologizante" (Silva et al, 2018, p. 41).

Assim, acreditamos que atividades como as que foram desenvolvidas pelo NUCH em 2018 têm papel indispensável nas abordagens de temáticas como gênero, sexualidade e educação, vendo-as como potentes possibilidades de novos construtos sociais, contribuindo, assim, para se pensarem novos processos de democratização da educação. Mais importante do que uma educação para a diversidade é trabalhar as diferenças na educação. 


\section{Referências}

BRASIL. Caderno Escola sem Homofobia. Livro de conteúdo. Brasília: SDH, 2011. Disponível em: < http://www.acaoeducativa.org.br/fdh/wp-content/uploads/2015/11/kitgay-escola-sem-homofobia-mec1.pdf>. Acesso em: 12 jun. 2019.

BRASIL. Parâmetros Curriculares Nacionais: pluralidade cultural, orientação sexual. Secretaria de Educação Fundamental. Brasília: MEC/SEF, 1997.

JESUS, J. G. Orientações sobre a população transgênero: conceitos e termos. Brasília: Autora, 2012.

LOURO, G. L. Gênero, sexualidade e educação: uma abordagem pós-estruturalista. Petrópolis: Vozes, 1997.

NASCIMENTO, M. M.; FERNANDES, F. B. M. Entre o saber e o fazer: extensão universitária, intervenção comunitária e engajamento político-feminista. Revista Feminismos, v.3, n.1, p.124-134, 2015.

SILVA, R. G.; SILVA, I. J. S.; FERNANDES, D. P. S. Educação sexual: caminhos pedagógicos de gênero e sexualidade no Ensino Médio. Revista Educação e Transformação, v.3, n.1, p.35-48, 2018.

SILVA, T. T. Documentos de identidade: uma introdução às teorias do currículo. 2. ed. Belo Horizonte: Autêntica, 2004.

UNESCO. Diversidade Sexual na Educação: problematizações sobre a homofobia nas escolas. Brasília: Ministério da Educação, Secretaria de Educação Continuada, Alfabetização e Diversidade, 2009.

\section{Notas}

${ }^{1}$ Hoje referidas como Infecções Sexualmente Transmissíveis - ISTs. 